\title{
Lung Transplantation in a Patient with Fibrosing Alveolitis
}

\author{
P. HUGH-JONES, A. M. MACARTHUR, P. A. CULlUM, S. A. MASON, W. A. CROSBIE, \\ D. C. S. HUTCHISON, M. C. WINTERTON, A. P. SMITH, B. MASON, L. A. SMITH
}

British Medical fournal, 1971, 3, 391-398

\section{Summary}

The transplantation of the right lung into a man aged 40 who was suffering from cryptogenic fibrosing alveolitis is described. Before transplantation he had been dependent on oxygen, even at rest, for 24 hours a day for almost two years. The donor was a boy of 16 years who had had a fatal cerebral haemorrhage. The transplanted lung functioned perfectly from the time of operation until the patient's sudden death two months later from an overwhelming haemoptysis apparently from a small peribronchial abscess rupturing into the pulmonary artery. By the third postoperative week the patient had been able to walk unaided and without distress outdoors. The problem of difierentiating infection from incipient rejection is discussed. We conclude that clinically successful lung transplantation can be achieved, but only if the problems of lung function, infection, and immunosuppression can all be overcome.

\section{Introduction}

Since the first human lung transplant was made eight years ago (Hardy et al., 1963) we believe that a total of 27 have been performed in various countries of the world (Organ Transplant Registry, 1971). In contrast to the accepted therapeutic value of kidney transplantation for terminal renal \footnotetext{
King's College Hospital Medical School, Denmark Hill, London
S.E.5

P. HUGH-JONES, M.D., F.R.C.P., Consultant Physician and Director, Pulmonary Research Unit

A. M. MACARTHUR, F.R.C.s., Consultant Thoracic Surgeon

P. A. CULLUM, F.R.C.S., Consultant Thoracic Surgeon

S. A. MASON, F.F.A. R.C.S., D.A., Consultant Anaesthetist

W. A. CROSBIE, M.B., M.R.C.P. (LOND., ED.), Lecturer in Medicine,

Pulmonary Research Unit

D. C. S. HUTCHISON, M.R.C.P.GLASG., Lecturer in Medicine, Pulmonary Research Unit

M. C. WINTERTON, M.R.C.P., Senior Registrar

A. P. SMITH, M.B., M.R.C.P., Research Assistant, Pulmonary Research Unit

B. MASON, M.R.c.P., Registrar
L. A. SMITH, A.I.S.T., Research Assistant, Pulmonary Research Unit
}

failure, lung transplantation, with one notable exception, has not been of any real value to the patients, though the operation was nearly always technically successful.

Respiratory failure accounted for most of the early deaths after operation and infection for nearly all the rest (Wildevuur and Benfield, 1970). Respiratory failure usually arose when one lung was transplanted into patients with terminal air-flow obstruction because of the very different compliance and airways resistance of the transplanted and the remaining lung which produced gross imbalance between the distribution of gas and blood in the two lungs (most of the inspired air going to the original lung, but most of the blood to the new one) or the new lung was simply compressed by overinflation of the old. Such blood gas disturbance after operation is at present the major contraindication to human lung transplantation (Bates, 1970). Infection, both bacterial and viral, was also a major hazard (Hardy et al., 1970) and readily occurs in the lung from organisms inhaled by the patient, who is made vulnerable to their attack because of the immunosuppression necessary for the transplant, or they may already be present in the donor or in the recipient's remaining lung. Rejection has rarely been the cause of failure, and only 5 out of 16 patients reviewed from necropsy studies showed any histological evidence of an immune change (Veith, 1970). There seems to be no reason why a lung graft should not do as well as a kidney graft, provided the postoperative functional and infective problems are overcome and correct immunosuppression is given, though the problem of distinguishing threatened rejection from infection during the critical few weeks after operation is paramount, and remains one of the major obstacles to clinical success (Hutchin et al., 1971).

Here we present a preliminary account of a transplant of a right lung into a 40-year-old man who was moribund from fibrosing alveolitis of unknown cause. He survived with remarkably good lung function for two months after operation, though before it he had been completely sedentary and dependent on continuous oxygen for about two years.

We thought lung transplantation to be ethically justified in his case, in spite of the generally poor previous clinical results from the operation, because he had a progressive and incurable disease which had produced, at his relatively early age, a state of complete oxygen dependency. Careful assessment of the function of both his lungs made us believe that 
he, like the Belgian patient who lived for 10 months after operation (Derom et al., 1969), would survive the operation without blood gas disturbance. Thus when an uninfected and well-functioning donor lung became available we recommended the operation, to which he agreed, realizing full well its hazards.

\section{Case Report}

The patient, a 40-year-old Iraqui living and working in London, was first seen in 1966 when he was 36 years old. He had been well until the age of 15 years when he noticed clubbing of his fingers. The clubbing became progressively more noticeable, but he had no other symptoms till he was about 30 when he developed undue shortness of breath on exertion which had become severe by the time we first saw him. He had had some blood-staining of his sputum for the previous six months and occasional pains in his joints and some swelling of his ankles. He had always lived and worked in Baghdad, until in the course of his work he went to Russia and Greece and then finally to London. He had had typhoid and malaria in the past and had smoked up to 60 cigarettes a day but had stopped smoking completely about a year previously. He had never been exposed to asbestos or other industrial agents apt to cause pulmonary fibrosis and there was no family history of finger clubbing. He had had radiographs, including bronchography (which had suggested widespread basal bronchiectasis) performed under Professor Farhan Bakir, Dr. Kontaxis, and Dr. Alfakhri in Baghdad, where the provisional diagnosis of an unusual variety of interstitial fibrosis, affecting mainly the lower lobes, had been made. We, too, felt that cryptogenic fibrosing alveolitis was the most probable diagnosis, but in view of his age, disability, and prognosis it was important to try to make a definite diagnosis and to exclude other more treatable conditions (such as bronchiectasis causing clubbing and haemoptysis from, say, hitherto unsuspected achalasia of the oesophageal cardia, or pulmonary schistosomiasis) and to exclude the possibility of an alveolar cell carcinoma having arisen. Thus in 1966 he had the following investigations.

Radiology. - There was fine nodulation in both lung fields, maximal in the middle and lower zones, with the diaphragms raised and the lesser fissure depressed, so that most of the lung field represented the upper lobes (Fig. 1). Bronchography was not repeated.

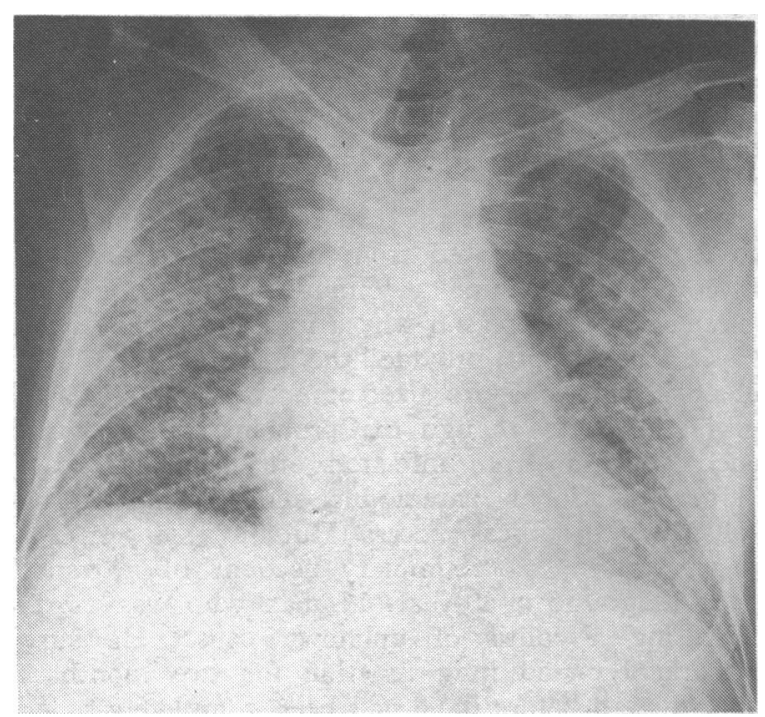

FIG 1.-Posteroanterior chest radiograph before operation.

Laboratory investigations excluded schistosomiasis and other conditions unusual in Britain.

Overall Lung Function.-The results (Table 1) show the typical changes of stiff lungs, with a gas transfer deficit, giving a low car-
TABLE I-Overall Lung Function Tests in 1966

\begin{tabular}{|c|c|c|c|c|c|c|c|c|}
\hline & & & & & & & & $\begin{array}{c}\text { Predicted } \\
\text { Normal }\end{array}$ \\
\hline $\begin{array}{l}\mathrm{FEV}_{1} \text { (litres)... } \\
\text { VC (litres) } \\
\text { FEV/VC }(\%) \\
\text { TCo(ml/mm } \mathrm{Hg} / \mathrm{m} \\
\text { Static lung complia }\end{array}$ & $\begin{array}{c}\cdots \\
\cdots \\
\text { ain) } \\
\text { iance (1. }\end{array}$ & $\begin{array}{l}\cdots \\
\because \\
\cdots \\
. \mathrm{cm} \mathrm{H}\end{array}$ & $\begin{array}{l}\cdots \\
\cdots \\
2 \\
2\end{array}$ & $\begin{array}{l}\ldots \\
\because \\
\cdots\end{array}$ & $\begin{array}{l}\ldots \\
\cdots \\
\cdots\end{array}$ & $\begin{array}{l}\cdots \\
\cdots \\
\cdots\end{array}$ & $\begin{array}{l}1 \cdot 84 \\
2 \cdot 1 \\
87 \\
9 \cdot 0 \\
0 \cdot 07\end{array}$ & $\begin{array}{c}3.6 \\
4 \cdot 2 \\
\text { About } 75 \\
29 \cdot 5 \\
0.3\end{array}$ \\
\hline \multicolumn{9}{|c|}{ Exercise Test (maximum $=300 \mathrm{~kg}-\mathrm{m} / \mathrm{min}$ ) } \\
\hline 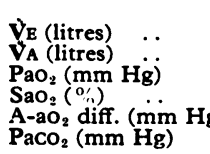 & $\begin{array}{c}\ldots \\
\ldots \\
\ldots \\
\ldots\end{array}$ & $\begin{array}{l}. \\
\cdots \\
\cdots \\
\cdots \\
\cdots\end{array}$ & $\begin{array}{l}\cdots \\
\cdots \\
\cdots \\
\cdots\end{array}$ & $\begin{array}{l}\cdots \\
\because \\
\cdots \\
\cdots\end{array}$ & $\begin{array}{l}\ldots \\
\cdots \\
\cdots \\
\cdots\end{array}$ & $\begin{array}{l}\because \\
\because \\
\because \\
\cdots \\
\cdots\end{array}$ & $\begin{array}{c}\text { Resting } \\
19 \\
9 \\
76 \\
95 \\
40 \\
33\end{array}$ & $\begin{array}{c}\text { Exercise } \\
62 \\
45 \\
46 \\
78 \\
64 \\
33\end{array}$ \\
\hline
\end{tabular}

bon monoxide transfer (Tco) and hyperventilation associated with a fall in arterial oxygen tension and a large alveolar-arterial gradient for oxygen on exercise.

Regional Lung Function at Bronchoscopy.-This was measured with a mass spectrometer, with the bronchoscopy performed under local anaesthesia (West, 1960; Hugh-Jones, 1967). The bronchial tree appeared anatomically normal, but the gas flow into both lower lobes was grossly reduced so that about $85 \%$ of the ventilation was going to the two upper lobes, while the blood flow to the lower lobes was even more reduced, giving the characteristic B pips on the spectrometer $\mathrm{O}_{2}$ and $\mathrm{CO}_{2}$ traces (West and HughJones, 1959).

All the above investigations pointed to a severe, progressive, fibrosing alveolitis of unknown cause, almost obliterating the function of both lower lobes of the lungs but partly sparing the upper lobes. After careful consideration thoracotomy was advised for open lung biopsy; firstly, to prove the diagnosis (and exclude complicating alveolar cell carcinoma so far as possible), and, secondly, because it might be possible to remove a source of haemoptysis or conceivably, by lower lobectomy, to improve the mechanics of the lung if the upper lobes were largely free from the disease process. At thoractomy on 30 July 1966 there was a free pleura, but the right lower lobe was shrunken to about half normal size and poorly aerated. It was impossible to inflate it further by vigorous inflation through the endotracheal tube. It felt rubbery but coarsely granular. The upper and middle lobes were similarly affected, but much less severely. There was no indication for lobectomy so a biopsy was simply taken from the posterior basal segment of the lower lobe. Histology was typical of a fibrosing alveolitis with pronounced squamous metaplasia of the bronchial mucosa.

\section{Preoperative Course}

Following these investigations in 1966 he was put on $15 \mathrm{mg}$ of prednisone daily and weight reduction was recommended with a low calorie and low carbohydrate diet. In spite of these measures both his lung function and clinical state deteriorated and by 1967 he was started on potassium para-aminobenzoate as well as the prednisone and given a portable oxygen set so that he could continue working at the Embassy. His resting arterial $\mathrm{Po}_{2}$ was $53 \mathrm{~mm} \mathrm{Hg}$ falling to $39 \mathrm{~mm} \mathrm{Hg}$ on gentle walking, though with the portable oxygen set the figures were, respectively, 76 and 60 $\mathrm{mm} \mathrm{Hg}$.

By 1969 we started him on $50 \mathrm{mg}$ of azathioprine a day as well as the prednisone which he maintained until the transplant operation in an effort to halt the relentless progress of the disease. Following the success of the Belgian lung transplant, we considered the possibility of transplant for him at a later date, though he was then still working daily and using portable oxygen. By 1970 his $\mathrm{FEV}_{1}$ had fallen to $1.4 \mathrm{l}$, his vital capacity to $1.5 \mathrm{l}$. while his total lung capacity remained at about 2.51 . with an FRC of 1.31 . and RV of 0.91 . The CO transfer was impossible to measure but he extracted only $6 \%$ per breath of the carbon monoxide in a mixture with air. His E.C.G. had shown slight right ventricular hypertrophy with an $S$ wave dominant in all precordial leads. Though his haemoglobin remained raised at 18.2 $\mathrm{g} / 100 \mathrm{ml}$, his blood volume, measured by Professor W. M. Davidson and Dr. P. Flute using (125I-albumin), was $4.7 \mathrm{l}$. but the red cell mass of 1.951 . was within the normal range of $31 \mathrm{ml} / \mathrm{kg}$. 
He was finally forced to stop all work for about two years and became dependent on oxygen for 24 hours a day. During the few months before transplant it became difficult to supply him with enough oxygen even at complete rest, he had difficulty in eating or in cleaning his teeth, and he became deeply cyanosed and exceedingly breathless if he took the mask off. Eventually he was consuming no fewer than twenty $100 \mathrm{ft}^{3}\left(2.83 \mathrm{~m}^{3}\right)$ cylinders of oxygen a week. He was admitted to hospital moribund from a minor chest infection two weeks before transplant but recovered with antibiotics. He became so cyanosed and breathless without oxygen that it was then impracticable to measure his arterial blood gas tension breathing air.

\section{Lung Donor}

After the patient accepted the possibility of lung transplant and had had his blood group and tissue type recorded (with the help of Professor Davidson and his staff, and through Professor $\mathbf{R}$. Batchelor and Mr. M. Bewick of Guy's Hospital) he said he had "died" from all useful life two years ago and was willing to accept the risk. He waited nine months for the operation. We had hoped for a lung, from a cerebrally dead patient, which had been ventilated for less than 24 hours, which was a good tissue match, was without obvious infection, and appeared, clinically, to be functioning well. Only four lungs of a compatible blood group became available during the nine months: the first we refused on grounds of tissue typing, the second because of infection and poor clinical state, and the third because of the old age of the donor and the clinical state of the lung.

At about 5 a.m. on 26 March 1971 a boy aged 16 years was sent to this hospital after he had been found unconscious on the floor following an intense headache and vomiting. He was said to have had a similar intense headache about a week before. On arrival his breathing had stopped but his heart was still beating so he was immediately ventilated. Lumbar puncture produced heavily blood-stained cerebrospinal fluid. He was transferred to the intensive care unit but there was no improvement in his condition, and his pupils remained dilated and fixed. The physicians in charge considered him to be cerebrally dead by 9 a.m. but sought the opinion of the consultant neurologist, who agreed. His electroencephalogram showed no response. Subsequently, when there was no possibility of resuscitating the patient and as a possible donor role was then considered, both a further electroencephalogram and a cerebral angiogram were done that afternoon. The latter showed that there was no cerebral blood flow at all. Only when the physicians in charge of him had no doubt whatsoever about cerebral death for many hours were the transplant team notified and the permission of his relatives sought early that evening to use organs. The coroner was then informed when this permission had been given.

The recipient's blood group was B positive, the donor's $\mathbf{O}$ positive; the recipient's tissue type HLA 2, 3 on one sublocus with two unknown factors on the other; the donor's tissue type HLA 8 and $\mathrm{BB}$ an one with 2 and an unknown on the other. Thus there were potentially three major mismatches unless the homozygous state or common missing factors meant only two. Though the tissue match was not as good as we would have liked, the excellent state of the lung, short time of ventilation, and lack of infection, together with the hazardous clinical condition of the recipient and the paucity of potential donors, determined us to recommend the transplantation to the recipient. This he agreed to.

\section{Operation}

By 8 p.m. the transplant team, operating theatres, pump oxygenator (in case of need), and respiratory laboratory were ready. Anaesthesia.-The problem was how to anaesthetize a patient who was dependent on pure oxygen inhalation, at rest, for survival. A left Robertshaw double-lumen intratracheal tube was accepted so that the patient could use both lungs until perfusion, but the anaesthetist could inflate one lung thereafter, as required. The only premedication was $10 \mathrm{mg}$ of diazepam subcutaneously to allay anxiety, given at 8.35 p.m. The anaesthetic was started at 9.20 p.m. and induced by methohexitone $80 \mathrm{mg}$ with suxamethonium chloride for insertion of the double-lumen tube. Anaesthesia was continued by intravenous phenoperidine and pancuronium bromide as the relaxant.

\section{OPERATIVE PROCEDURE}

The recipient's chest was opened through the previous thoracotomy scar and the lung approached through the fifth right intercostal space. After arterial blood gas results, cardiopulmonary bypass was agreed to be necessary and this was established with a Temptrol oxygenator (right atrium to left femoral artery) with flows ranging from 1 to $3 \mathrm{l} / \mathrm{min}$. The patient's condition immediately improved and the right lung was then excised at the hilum. It was grossly shrunken and looked and felt not unlike a hobnail liver. While all this was proceeding in the theatre, the donor lung was removed in another room after the ventilator had been stopped and cardiac standstill had takn place to comply with medicolegal requirements. The donor lung was implanted, and arterial, venous, and bronchial anastomoses were carried out in that order. Because of pronounced dilatation of the pulmonary artery the main trunk of the donor lung was anastomosed end to end to the recipient artery distal to its first upper lobe branch. The veins were anastomosed with an atrial cuff from the donor which had to be trimmed to fit the rather small left atrium of the recipient. A continuous mattress suture (Ethicon 6591) was used and all air aspirated before removing the clamps.

After completion of the vascular anastomoses the clamps were removed and the bronchial anastomosis was carried out. This was performed with interrupted stitches of Tevdek 79-716 with the suture line made at a point about $1 \mathrm{~cm}$ from the upper lobe bronchus and $1 \mathrm{~cm}$ from the tracheal bifurcation. Disproportion was again a problem but was overcome by making a long oblique anastomosis. No attempt was made to preserve bronchial blood supply, and the anastomotic line was covered by mediastinal pleura. The implanted lung inflated easily and the patient came off bypass with no difficulty. The chest was closed with apical and basal drains. The total time of perfusion at normal temperature was 114 minutes, and the warm ischaemic time till blood flow was re-established in the donor lung was 59 minutes.

\section{OPERATIVE COURSE}

While anaesthesia was being induced at 9.20 p.m. with the patient breathing oxygen he had a $\mathrm{PaO}_{2}$ of $59 \mathrm{~mm} \mathrm{Hg}$ ( $\mathrm{SaO}_{2} 83 \%$ ), $\mathrm{Pco}_{2}$ of $83 \mathrm{~mm} \mathrm{Hg}$, and pH 7.2. After taking bacteriology swabs of his throat, nose, rectum, eyes, and urine he entered the operating theatre at 10.15 p.m. and the ventilation was increased to no less than $14 \mathrm{l} . / \mathrm{min}$ of pure oxygen, yet his arterial blood gases were $\mathrm{Po}_{2} 112$ and $\mathrm{PCO}_{2} 78 \mathrm{~mm} \mathrm{Hg}$. With the lung retracted and the chest open the $\mathrm{PO}_{2}$ fell to the very low figure of $39 \mathrm{~mm} \mathrm{Hg}$ so that bypass was inevitable. Once established the $\mathrm{Po}_{2}$ rose to 65 (saturation $93 \%$ ) and the $\mathrm{PCO}_{2}$ fell to $49 \mathrm{~mm} \mathrm{Hg}$. His right lung was removed by midnight and the new lung was in place by 12.15 a.m., when ampicillin and cloxacillin were given intravenously. The new lung was re-perfused at 1 a.m. and he came off bypass at 1.40 a.m. On his new lung, ventilated with oxygen, he had a saturation of $97 \%, \mathrm{PaO}_{2} 88, \mathrm{PCO}_{2} 34 \mathrm{~mm} \mathrm{Hg}$, and pH 7.45. By 3.45 a.m. the pancuronium was reversed and he breathed oxygen spontaneously, with the endotracheal tube in, giving blood gas values at 3.54 a.m. of $\mathrm{SaO}_{2} 98 \%, \mathrm{Po}_{2} 134, \mathrm{PcO}_{2} 75 \mathrm{~mm} \mathrm{Hg}$. At 4.15 a.m. he was conscious and responding to speech but the anaesthetic tube was left in. By 4.45 a.m. he was losing blood freely from the thoracic drain so he was re-anaesthetized and the chest reopened at 4.50 a.m. By then he was hypotensive with a systemic pressure of $30 \mathrm{~mm} \mathrm{Hg}$ and a C.V.P. of $-5 \mathrm{~cm} \mathrm{H}_{2} \mathrm{O}$ after the bleeding. By 6 a.m. the chest was closed again and a repeat chest $x$-ray film was satisfactory. The anaesthetic tube was removed at 6.35 a.m. when he was breathing spontaneously, talking, and passing urine satisfactorily, and he was returned to the ward with oxygen by mask. He had had a measured total blood loss of about $6.5 \mathrm{l}$. which was replaced by 81 . of acid-citratedextrose stored blood.

Back in the ward at 8 a.m. and breathing $71 . / \mathrm{min}$ pure oxygen by mask spontaneously, he had an arterial oxygen saturation of $95 \%\left(\mathrm{PO}_{2} 80, \mathrm{PcO}_{2} 60 \mathrm{~mm} \mathrm{Hg}, \mathrm{pH} 7 \cdot 31\right)$. He was again losing much blood through the chest drain so fresh frozen plasma and 6 pints (3.4 1.) of fresh blood from relatives was later given. By the evening his breathing rate had gone up, from $25 / \mathrm{min}$ that morning to $60 / \mathrm{min}$ and it was evident that blood clot was restricting his new lung. Thus his chest was reopened at 9.45 p.m. and the clot evacuated. It was then possible to give him a mixture of $50 \% \mathrm{O}_{2} / \mathrm{N}_{2} \mathrm{O}$ to breathe and his saturation remained at 
$95 \%$ with a $\mathrm{PCO}_{2}$ of $50 \mathrm{~mm} \mathrm{Hg}$ and he was finally returned to the ward by 10.40 p.m. on 27 March.

The pulmonary anastamoses were found to be intact on both occasions when the chest was reoponed, but on the first some bleeding came from the inferior pulmonary ligament, and on the second the skin wound oozing ceased after the transfusion of fresh blood.

\section{Postoperative Course}

The patient's ward was a room with adjoining bathroom, both with filtered positive-pressure ventilation. All staff before entering changed their clothes for sterile ones, scrubbed, and wore surgical masks and all equipment taken in was gas sterilized. Food, supplied to us from Hammersmith Hospital, had been made bacteriologically sterile by neutron irradiation. Daily radiographs were taken by inserting the $x$-ray tube through a polyethylene bag into the room.

We have attempted to chart the salient points in his postoperative course in Fig. 2. The clinical grade presented at the top of the figure represents an independent assessment by the medical staff and the physiotherapists who visited him daily. There was never disagreement by more than one grade between the two. In the few cases where there was such a difference, the lower grade is recorded. The basis is shown in Table II.

The result of the transplant can fairly be said to have been excellent. From the patient we knew before transplant at clinical grade 5 (Fig. 3), he was, by the third day, breathing quietly and had a normal colour without oxygen. He was able to walk about the room by the fourth day. Initially, he tended to feel panicked without the mask, so dependent had he become, even though his blood gases were satisfactory. By the middle of the fourth week he was taken for a drive into the centre of London and subse-

Day 1357911131517192123252729313335373941434547.495153

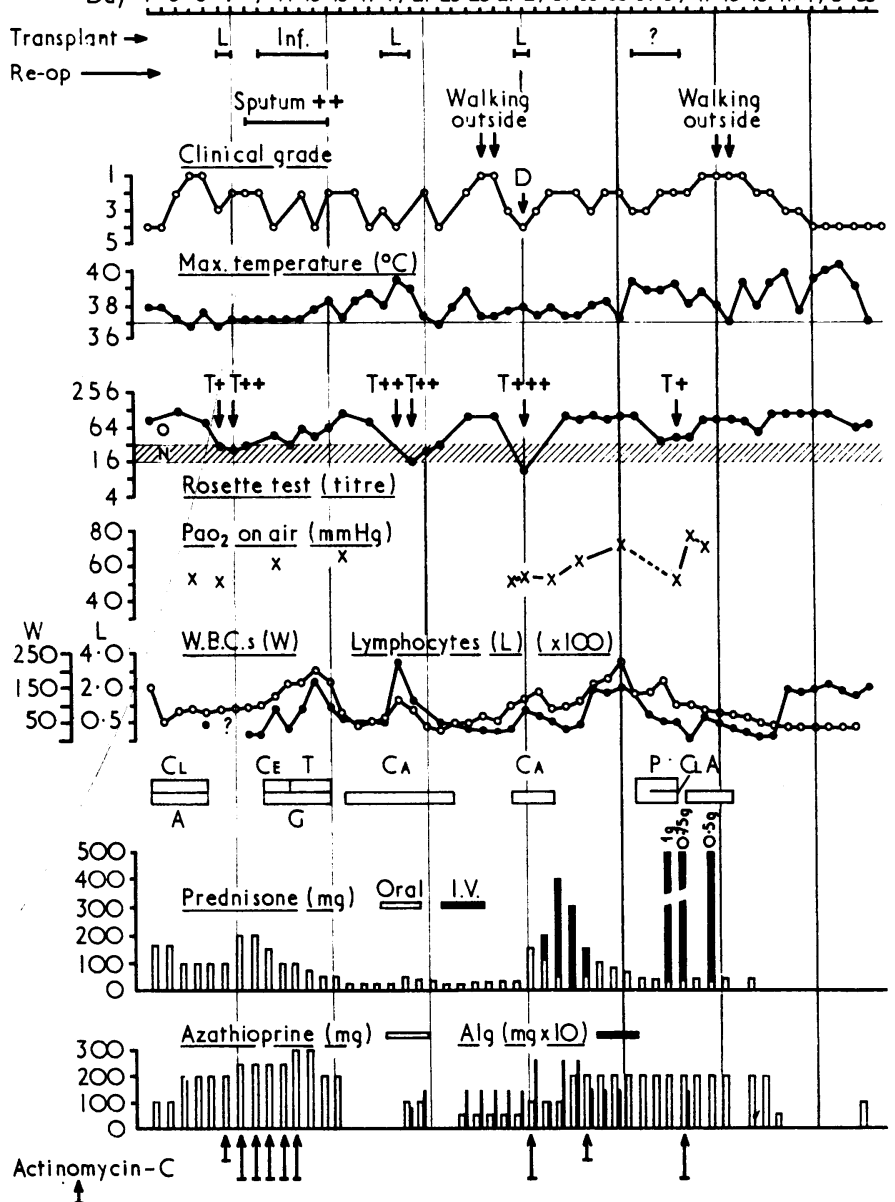

FIG. 2-Summary of postoperative clinical course. At top: $L=$ Periods of appearance of presumed thymic lymphocytes and incipient rejection. INF $=$ Chest infection. $D=$ Severe mental depression. For other details see text. At bottom: $\mathrm{A}=$ Ampicillin. $\mathrm{CA}=$ Carbenicillin. $\mathrm{CE}=$ Cephaloridine. $\mathbf{C L}=$ Cloxacillin. $\mathbf{P}=$ Penicillin. $\mathbf{T}=$ Tetracycline. In Rosette test: $O$ or above is optimum supression. $\mathrm{N}=$ Normal range. $-0-0-0=$ Total W.B.C.s. $-0-0-0=$ Lymphocytes.
TABLE II-Clinical Grade used Postoperatively

Grade 1: Feels well. Able to walk without oxygen and without distress. Feels able to go outside.

Grade 2: Tired but otherwise reasonably well. Slight breathlessness. Mainly sedentary.

Grade 3: Confined to bed. Wanting to use oxygen.

Grade 4: Breathless and distressed. In bed. Feeling ill. Needing oxygen.

Grade 5: Oxygen-dependent at rest. Severely distressed and cyanosed without oxygen.

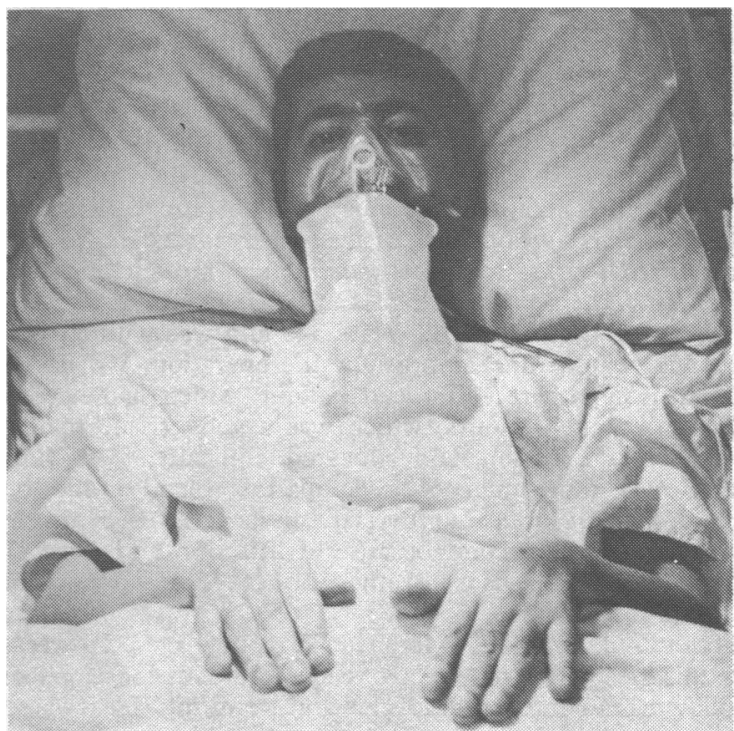

FIG. 3-Completely oxygen dependent just prior to operation.

quently for a short walk in a local park (Fig. 4). Six weeks after the operation he walked briskly up steps and about a quarter of a mile $(400 \mathrm{~m}$.) without breathlessness to see a new flat to which we had hoped to discharge him.

On the other hand, his postoperative course was complex, as Fig. 2 shows, and he had many periods of illness. The true cause of these ill periods we cannot know. We have given our interpretation of them in Fig. 2 above the clinical grade. Here L represents our belief that he was producing thymic-dependent lymphocytes active against the graft, and treatment prevented progress towards rejection, while INF represents a period of infection, likewise treated. The treatment given is shown in the bottom two parts of the figure. Our interpretation is based mainly on the combination of the changes in the clinical grade and the rosette test, total white cell and lymphocyte count, temperature, and arterial oxygen tension breathing air as shown, together with other information such as chest signs, haematology, sputum culture, biochemistry, and daily radiographs.

\section{IMMUNOLOGICAL CHANGE}

This was mainly assessed by the rosette test (Munro et al., 1971). The results shown in Fig 2 represent the titre of lymphocyte suppression, so that a high titre, at or above the optimum line shown, represents satisfactory suppression, whereas a fall into the normal range or below means inadequate titre measurements. The number and qualitative character of the lymphocyte rosettes were visually determined and the appearance of lymphocytes believed to be associated with incipient rejection was noted. These are recorded as a $\mathrm{T}+$ in Fig. 2. It can be seen that on the three occasions shown at the top of Fig. 2 , on about days 6,18 , and 28 , there is the combination of (1) a low titre in the rosette test with the appearance of $\mathrm{T}$ lymphocytes, together with (2) a rise in the absolute number of circulating lymphocytes (though the latter were not recorded on the first occasion), (3) a fall in clinical grade, (4) a low PaO.2 breathing air (though the latter was not recorded on the second occasion), and (5) persistent rhonchi in the right chest on two occasions. This same combination of factors may be present on day 37 but not so definitely.

Each time this combination of factors occurred the incipient possibility of rejection was presumed and treatment given (though at no time was there any of the hilar flare on the chest $x$-ray film 
believed to be characteristic of rejection). On the first occasion treatment was simply an increase in the prednisone and the azathioprine since actinomycin-C was being used concurrently. The rosette test appeared to respond slowly and the patient coincidentally improved. On the second occasion antilymphocytic globulin (A.L.G.) became available and reliance was placed on this (and azathioprine with prednisone). On the third occasion, when the presumption seemed very definite (in view of the ill and severely mentally depressed patient whose rosette test suddenly showed almost total lack of suppression and abundant $\mathrm{T}$ lamphocytes), he was given up to $0.5 \mathrm{~g}$ of intravenous prednisone and the A.L.G. that he was then receiving was doubled. On the more doubtful fourth occasion, when he had had a high unexplained fever for three days and there was no certain evidence of infection, nor response to antibiotics, he was treated on two successive days with $1 \mathrm{~g}$ and $0.75 \mathrm{~g}$ respectively of intravenous prednisone.

\section{USE OF IMMUNOSUPPRESSANTS AND A.L.G.}

We had intended to follow the regimen successful in the Belgian case using an average of $200 \mathrm{mg}$ of azathioprine daily with 40-60 $\mathrm{mg}$ of prednisone orally and actinomycin-C $200 \mathrm{mg}$ daily for the second week and, thereafter, once weekly. We initially had no satisfactory source of A.L.G. But by the 15th day we were worried by a fall in the total white cells so stopped the azathioprine (incorrectly, we believe in retrospect), fearing its delayed action, and at the same time reduced the prednisone not only because of glycosuria but because the patient had had a definite chest infection from about the 9th to the 14th day.

Because of these difficulties with the drugs and because the lymphocytes appeared not to be differentially suppressed relative to the total white cells an urgent search was made for A.L.G. which we believed to be both effective and safe. Finally, when we approached Sir Michael Woodruff he authorized Dr. David Long, of Messrs. Burroughs Wellcome Ltd., to supply us with some of their clinically tested T.D.1 batch of horse A.L.G. This was started on day 18 (just as the rosette test was deteriorating) in the manner suggested by the manufacturers-on the first day at $10 \mathrm{mg} / \mathrm{kg}$ intravenously (with chlorpheniramine and hydrocortisone in the drip to minimize reactions) and, when that was taken without undue reaction, it was given on subsequent days at the full dose of $20 \mathrm{mg} / \mathrm{kg}$, though on three occasions (during the period of the very definite lack of active lymphocyte suppression) the dose was doubled.

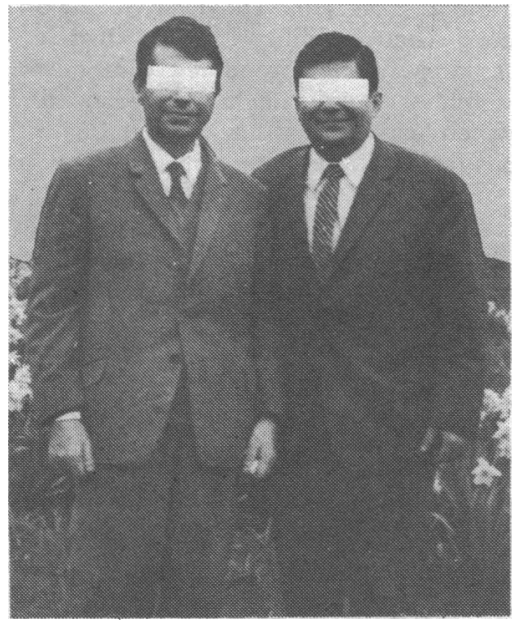

FIG. 4-With his brother (right) three and a half weeks after right lung transplantation.

On no occasion, save one, was there a very alarming reaction to the infusion of A.L.G., though distressing shivering or rigors occurred after the infusion in spite of the antihistamine drug and hydrocortisone. These rigors were controlled by $20 \mathrm{mg}$ of chlorpheniramine intravenously, but diazepam, which had been recommended, was without effect. The one bad reaction was when A.L.G. had appeared to be tolerated well by infusion and an attempt was made to give it as a diluted intravenous injection, exceedingly slowly from a syringe. It was stopped after 16 days because a high anti-horse-serum titre was being produced, as estimated by Wellcome Research Laboratory, and though there was considerable horse IgG circulating its lymphotoxic efficacy was doubtful and there was worry about the possible effect of the horse serum reaction an the kidneys. The excretion of the A.L.G., labelled with iodine-125, measured by Mr. M. Clark of the department of medical physics, suggested it was eliminated in two days, but the measurement of the in-vivo circulating horse globulin by the Wellcome Research Laboratory suggested it remained almost three times that long. It was for this latter reason that it was considered safe to repeat the infusion during the possible lymphocytic crisis on day 37.

From just before the end of the A.L.G. administration we attempted to keep the azathioprine constant at $200 \mathrm{mg} /$ day and the prednisone at $40 \mathrm{mg}$ orally with added large transient intravenous doses of prednisone should incipient immunological reaction be suspected. Professor A. G. R. Sheil, of the University of Sydney, Australia, generously agreed to supply us with some of their goat A.L.G. (Sheil et al., 1971) which arrived by air on day 50, but was never used.

\section{INFECTION}

From previous accounts of human lung and kidney transplants we feared not only bacterial infection in the lungs, especially from pseudomonas, but virus infections and infection from less common pathogens. Swabs of the donor lung were sterile, the recipient appeared relatively free from lung infection at the time of transplant, and after the operation we attempted to maintain a sterile environment. There was only one definite period of infection, from about the 9th to the 14th day, when the sputum was increased in amount, frankly purulent, and growing Pseudomonas aeruginosa on culture, and the chest radiograph showed what appeared to be a small area of collapse consolidation below the lesser fissure in the new lung. He was treated with gentamicin (40 mg intramuscularly thrice daily) together with cephaloridine ( $\mathrm{g}$ intramuscularly twice daily) and subsequently teracycline instead ( $2 \mathrm{~g}$ orally/day). His fever fell and his clinical condition was excellent by day 14 so that the antibiotics were all stopped. Unfortunately, the fever started to rise again the next day so carbenicillin was substituted, because of reported resistance to the other antibiotics, at first intramuscularly ( $2 \mathrm{~g}$ four times a day for two days) and then, with a further rise of fever and pronounced deterioration in his general clinical condition to grade 4 (Fig. 2), $30 \mathrm{~g} /$ day intravenously with colistin inhalations as suggested by Pines et al. (1970).

In retrospect, and subsequently, we believe his state was from immune reaction and it improved remarkably soon after starting the T.D.I. horse A.L.G. Again on the 27th day we feared pseudomonas infection and restarted intravenous carbenicillin and colistin inhalations, but again, in retrospect, we believe this may have been an immunological deterioration.

We were concerned by his persistent bouts of fever (Fig. 2), and because of a blood culture growth first of a coagulase-negative staphylococcus in three bottles after one day (day 36) and then of Streptococcus faecalis (day 39) he was given penicillin (4 megaunits intravenously then 2 megaunits intramuscularly with cloxacillin $8 \mathrm{~g} /$ day orally) and ampicillin for the two findings respectively. We realize that these organisms could have been contaminants, but from the results of skin swabs of patient and doctors and because of the risks under immunosuppression we gave the antibiotics. There is now little doubt that his fever from day 35 to day 53 was caused by a pyaemia.

\section{CHEST $x$-RAY EXAMINATION}

The remarkable and gratifying feature of the daily postoperative chest radiograph (Fig. 5) was that there was no definite change since the time of transplant (apart from the small area of collapse consolidation between about days 9 and 14) and there was a transient increase in the small effusion under the wound and in the lesser fissure which disappeared after aspiration. The original lung remained contracted while the new lung was well expanded and showed a good excursion between inspiratory and expiratory films. But on day 52 an air pocket appeared near the 
medial aspect of the bronchial suture line, on tomographs, and we feared a peribronchial abscess.

\section{LUNG FUNCTION}

He had clear vesicular breath sounds over the new right lung throughout, with added persistent rhonchi on only two occasions, noted above, when we suspected incipient rejection. Over the left lung they were likewise clear in the upper third, but almost inaudible below where the original loud crepitations persisted. His arterial blood oxygen at rest and breathing air is shown in Fig. 2.

The highest oxygen tension was recorded on day 40 and the arterial blood that day showed a saturation of $96 \%, \mathrm{Po}_{2} 76 \mathrm{~mm} \mathrm{Hg}$, $\mathrm{Pco}_{2} 32 \mathrm{~mm} \mathrm{Hg}, \mathrm{pH} \mathrm{7.49}$, and plasma bicarbonate $32 \mathrm{mEq} / 1$. His $\mathrm{FEV}_{1}$ on the 45 th day was 1.61 . with a VC of 1.91 ., FEV/VC ratio $84 \%$, while his carbon monoxide transfer was $14.2 \mathrm{ml} / \mathrm{mm} \mathrm{Hg} /$ min (predicted normal 28) with a Kco value of 3.0. A-technetium${ }^{99} \mathrm{~m}$-labelled albumin scan (Fig. 6) on days 15 and 30 with a gamma camera was similar on the two occasions. It showed that the new lung had all the perfusion except for some to the apex of the old one. A xenon-133 scan, done at Hanımersmith Hospital on day 46, showed that the ventilation was distributed in balance with the blood and in the new lung both had a virtually normal distribution from apex to base (West, 1963). This finding was compatible with the clinical, radiological, and arterial blood gas results.

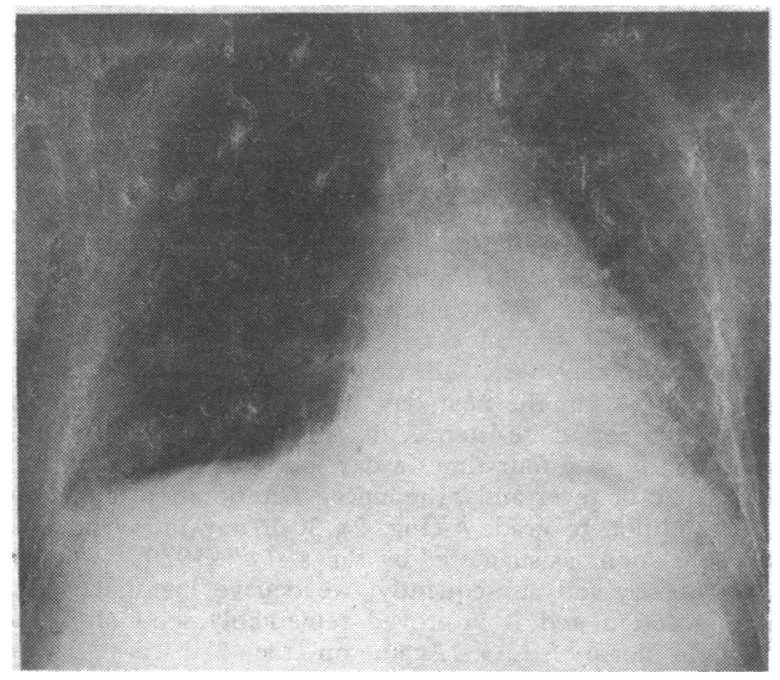

FIG. 5-Posteroanterior chest radiograph on day 8.

\section{ELECTROCARDIOGRAM}

Immediately after the transplant a right ventricular strain pattern developed but disappeared over the next few days. There was subsequently little change until the 38th day, when a transient atrial tachycardia was seen associated with flattening of $T$ waves over the precordial leads.

\section{METABOLISM AND ELECTROLYTES}

Following the high dose of oral steroids given for immunosuppression (we now think, incorrectly) the patient developed glycosuria and a raised fasting blood sugar level (which was easily controlled by small insulin doses) and then a high loss of urinary potassium (rising to $158 \mathrm{mEq}$ in 24 hours), which in spite of oral potassium supplements caused a fall of serum potassium. These difficulties ceased when the oral prednisone was reduced on the 10th day.

\section{HAEMATOLOGY}

In spite of the immunosuppression the daily platelet count was never seriously depressed. On the other hand, the haemoglobin, which was $18 \mathrm{~g} / 100 \mathrm{ml}$ before transplant, steadily fell during the first 10 postoperative days, from a constant level of about $15 \mathrm{~g}$ to about $11 \mathrm{~g}$ throughout the second, third, and fourth weeks and finally to the lowest level of $9 \mathrm{~g}$ on day 40, when he was given a transfusion of packed cells with improvement both in this measurement and in his general condition. From records of the packed cell volume and a knowledge of the considerable volume of blood which had to be taken for the necessary control of treatment most of the fall, but not all, could be accounted for from haemodilution and iron loss, in spite of the administration of oral iron tablets.

His Westergren E.S.R. remained below $20 \mathrm{~mm} / \mathrm{hr}$ during the first two weeks and thereafter showed a steady rise, with some fluctuation, to over $100 \mathrm{~mm} / \mathrm{hr}$ on some days during the last two weeks.

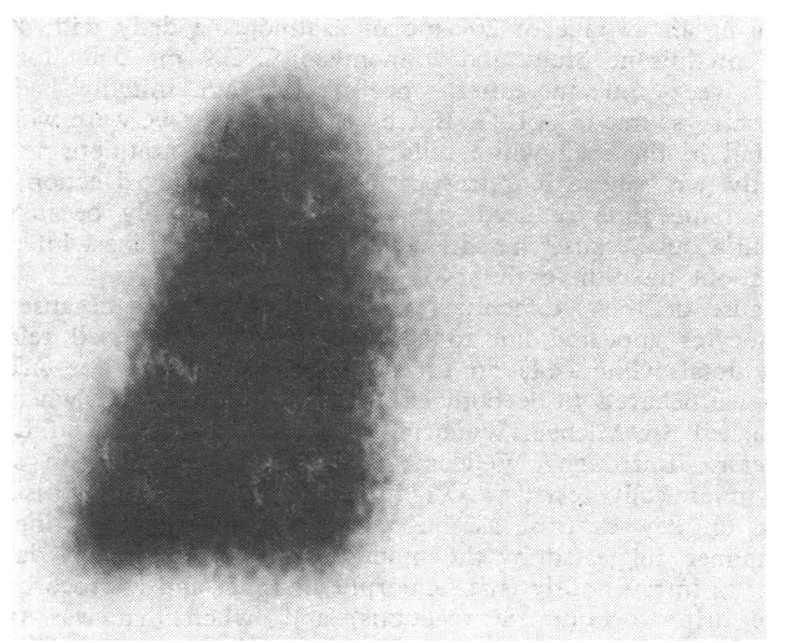

FIG. 6-Technetium-albumin scan taken with gamma camera on the 30th postoperative day showing virtually all the blood flow going to implanted right lung.

\section{CAUSE OF DEATH}

From day 35 the patient had been having a fever which persisted in spite of antibiotic treatment. However, it fell on day 53 and he felt much better that evening but he had a sudden severe haemoptysis at 11 p.m. This rendered him unconscious, he was then ventilated but at 4 a.m. he had a second and overwhelming haemoptysis which caused his unexpected death. The full postmortem findings are not yet complete but the pathologists (Dr. K. B. Shilkin from King's College Hospital and Professor Lynne Reid from the Institute of Diseases of the Chest) were able to find a small fistula from the bronchus to the pulmonary artery presumed to arise from a peribronchial abscess. The full findings will be published later.

\section{Discussion}

This patient, who survived two months after his transplant, was the second longest survivor, the longest being the Belgian patient who survived 10 months and was discharged from inpatient care. The transplanted lung in our patient functioned clinically well, and from general and regional tests virtually normally, so that his sudden and unexpected death was a great disappointment. This is especially so because it was from a minute peribronchial abscess which one would normally expect to rupture into the bronchus and be discharged and not, as it happened, to perforate into the pulmonary artery. Moreover, the pyaemic infection was being controlled, the fever had abated on the day of his death, and we had confidently expected to release him from hospital. But even this much was 
worth all the effort-for him as a patient and, in experience, for ourselves. We now feel confident that lung transplantation can succeed in carefully selected cases. The patient was resuscitated from an incurable and progressive alveolar fibrosis from which he was suffocating from lack of oxygen, and the practical problem of providing him with enough oxygen was becoming impossible. To see him directly after operation breathing freely without oxygen and with a normal colour was remarkable, and when he left hospital during the fourth postoperative week to walk about outside with no breathlessness, he remarked that it was the first time he had worn clothes in 18 months and he felt he was alive again after many years.

Our results depend on much previous work by others in animals and in man, and especially on the pioneering first human lung transplant (Hardy et al., 1963) and on the success of the Belgian case (Derom et al., 1969). We believe that our patient was clinically successful because extensive preoperative tests of lung function had shown the nature of his restrictive lung disease, so that we were confident that his own left lung would not become overdistended; because extreme care was taken to avoid introducing infection; and because we benefited from the experience in kidney and liver transplants of how to deal with rejection which was anticipated from daily observation of the reaction of the circulating lymphocytes by the rosette test. Even so, infection proved to be the obstacle to success.

Our case, like the Belgian one, showed that the patient's new lung could accept, without damage, the high perfusion from the moment of transplant caused by the high vascular resistance in the remaining lung. This was probably because the new lung was from a young donor and undamaged, since the experience of others has been different (Stevens et al., 1970). Our patient showed only a transient pattern of right ventricular strain on the electrocardiogram.

We experienced the problem of differentiating infection from incipient rejection common to all transplant patients. Clinical deterioration can be caused by either, and the tendency has been to increase the immunosuppressive regimen at the expense and risk of infection. Though we were initially in doubt about the interpretation and value of the rosette test, experience made us believe it to have been invaluable for anticipating rejection. We understand that in renal transplants rosette deterioration precedes loss of kidney function by up to 24 hours, but time must elapse for urine collection. It may well be from our results that a fall in arterial oxygen tension which can be measured immediately is an early warning sign of incipient rejection, though we, unfortunately, took insufficient samples, especially during the second week, to relate this to the rosette test. A fall in tension may also occur with pulmonary infection.

We attribute the avoidance of infection initially to the careful removal of as much chance of infection as possible by the aseptic condition in the ward, to no artificial mechanical ventilation, to daily physiotherapy, and to insisting that the patient breathed a high flow rate of filtered air or oxygen by mask when moving about the hospital and only breathing without this in the ward or outdoors. We would, in future, avoid giving as much steroid systemically as we did in this patient.

In retrospect, the immunosuppression seems to have been reasonably satisfactory and to have prevented rejection, though we would now not give such high oral doses of prednisone during the first 10 days but would rely on large intravenous "shots" which are lymphocytotoxic and quickly eliminated from the body (Bell et al., 1971) when the lymphocytes give warning of rejection. The T.D.1 A.L.G. seems to have been effective and the patient was very well soon after its administration was begun, though we have no proof of its efficacy. It seems that the recommended dose of $20 \mathrm{mg} / \mathrm{kg}$ differentially reduced the lymphocytes but was not enough to prevent a potential rejection crisis on day 28 , though the latter responded either to doubling the dose of A.L.G. or to intravenous prednisone injections. Further clinical trials of this A.L.G. seem warranted, but we could not afford to distinguish between its effect and that of prednisone in our lung transplant patient. Such a trial would have to be made in a renal transplant patient who could be put on the artificial kidney and later retransplanted from cadaver sources if irreversible rejection occurred.

One very important aspect of lung transplantation is the psychological effects. Not only must the patient be prepared for the psychological problems of having a foreign organ, but he must be prepared for the isolation, the discomfort of operation, and especially for multiple venous and arterial punctures. In future we would consider making a Scribner shunt at the time of operation to avoid the repeated venepunctures. Our patient was introduced to the isolation ward and the staff as soon as the operation was envisaged. His fortitude and emotional stability were admirable. Television, etc., act only as diversional treatment, and psychotherapy may be important. Our patient was seriously depressed on about day 27 and 28 . This could have been organic, from steroids, the immunological effects within his body, or psychogenic because, from going about London and feeling well, he was suddenly confined back to his room and had to endure further infusions when his veins were already painful from carbenicillin. The depression, during which he threatened to discharge himself, rapidly cleared either because of explanation and psychotherapy or because of the effect of the immunosuppression on his bodily state.

\section{Conclusion}

We conclude that lung transplantation in man will succeed, but until there is more basic knowledge about immunology, the preservation of lungs, and other problems it should be done only in most carefully selected circumstances. Even then it must not be lightly undertaken. The surgery itself is only one part of the problem, and for success it demands immense time and the co-ordination of the resources in many different fields: respiratory physiology, immunology, bacteriology, haematology, biochemistry, radiology, physiotherapy, and psychotherapy.

Four types of patient might benefit from transplantation. Terminal cases with progressive fibrosis (like our own and the Belgian case); patients with paraquat poisoning (like the Edinburgh case) if the poison has been eliminated; progressive pulmonary hypertension; and, finally and most interesting, advanced emphysema in young patients such as those suffering from $\alpha$-antitrypsin deficiency. The latter cannot be mimicked by animal work, and human experience has revealed its problems (British Medical fournal, 1970; Bates, 1970). We believe that by mass spectrometer sampling of the two lungs the ventilation-perfusion balance could be maintained directly after operation, and it is possible that in man the contralateral lung can be removed once the new lung is established. The transplantation of one lung in animals after simply anastomosing bronchus, pulmonary artery, and an atrial cuff with the pulmonary veins to the left atrium, without bronchial artery or lymphatic anastomosis, has been shown to be compatible with prolonged life and good function in many reports ever since the first successful mammalian transplant about 20 years ago (Juvenelle et al., 1951), provided the warm ischaemic time is kept short and adequate immunosuppression is given with azathioprine in allo-transplants.

If both lungs are transplanted or one transplanted and the other removed in animals then breathing is severely disturbed from alteration of respiratory reflexes, or pulmonary oedema can occur from the sudden blood flow into one lung. It remains to be shown whether this is true for man. 
We are grateful for help from Dr. J. Laws, Professor A. C. Cunliffe and his staff, Professor J. R. May, of Brompton Hospital, Dr. P. Croydon, of Messrs. Beechams Laboratories, Dr. S. Oram, Dr. P. Kidner, Professor C. H. Gray and his staff, and Professor W. Davidson and his staff. Many others helped us, especially the nursing staff and physiotherapists of King's College Hospital and the technical and secretarial staff of the pulmonary research unit. We wish to thank the Board of Governors and administrative staff for giving permission for this operation in a busy general hospital. Professor Lynne Reid, of the Brompton Hospital, has kindly agreed to do detailed pathological studies of the excised lung. We are especially indebted to Mr. M. Bewick, of Guy's Hospital, not only for the daily rosette test but for continued helpful advice about the immunosuppressive treatment.

\section{References}

Bates, D. V. (1970). New England fournal of Medicine, 282, 277. Bell, P. R. F., et al. (1971). Lancet, 1,876 .
British Medical fournal, 1970, 3, 600.

Derom, F., et al. (1969). Tijdschrift voor Geneeskunde, 25, 109.

Hardy, J. D., Webb, W. R., Dalton, M. L., and Walker, G. R. (1963). Fournal of the American Medical Association, 186, 1065.

Hardy, J. D., et al. (1970). Fournal of Thoracic and Cardiovascular Surgery,

60, 411.
Hugh-Jones, P. (1967). Bulletin de Physio-Pathologie Respiratoire, 3, 419.

Hutchin, P., Freezor, M. D., Walker, E. L., and Peters, R. M. (1971). Journal of Thoracic and Cardiovascular Surgery, 61, 476.

Juvenelle, A. A., Citret, C., Wiles, C. E., and Stewart, J. D. (1951). fournal of Thoracic Surgery, 21,111 .

Munro, A., et al. (1971). British Medical fournal, 3, 271.

Organ Transplant Registry (1971). American College of Surgery/National Institutes of Health, Chicago, Illinois.

Pines, A., Raafat, H., Siddiqui, G. M., and Greenfield, J. S. B. (1970). British Medical fournal, $1,663$.

Sheil, A. G. R., et al. (1971). Lancet, 1, 359.

Stevens, P. M., Johnson, P. C., Bell, R. L., Beall, A. C., and Jenkins, D. E. (1970). New England fournal of Medicine, 282, 245 .

Veith, F. J. (1970). Fournal of Thoracic and Cardiovascular Surgery, 60, 423.

Veith, F. J. (1970). Fournal of Thoracic and Cardiovascular
West, J. B. (1960). Fournal of Applied Physiology, 15, 976.

West, J. B. (1960). Fournal of Applied

West, . B. (1963). Lancet, 2, Apps. (1959). Journal of Applicd Physiology,

West, J. B., and Hugh-Jones, P. (1959). Journal of Applied Physiology,

Wildevuur, C. R. H., and Benfield, J. R. (1970). Annals of Thoracic Surgery, 9, 489 .

\title{
Ophthalmic Manifestations of the Battered-baby Syndrome
}

\author{
BRIAN HARCOURT, DAVID HOPKINS
}

British Medical fournal, 1971, 3, 398-401

\section{Summary}

Eleven battered babies who had ocular manifestations of their abuse are presented. Eight of these suffered a permanent impairment of visual function. Ten had extensive intraocular haemorrhage, and the importance of this physical sign in the diagnosis of the syndrome and in the development of a consequent visual handicap is emphasized.

\section{Introduction}

The battered-baby syndrome occurs in young children who have suffered physical trauma at the hands of their parents or guardians. Affected children often have severe permanent physical, mental, and emotional disabilities, and some die as a result of the abuse. It is clearly of the utmost importance that the diagnosis is never overlooked, and the characteristic association of some or all of the following features has been found most helpful: (1) the child is usually less than 2 years of age; (2) the general condition of the child is often indicative of neglect; (3) there is often a disproportionate amount of soft tissue injury; (4) there may be evidence that the injuries have occurred at different times, and, in particular, radiographic skeletal survey may show that a number of bony fractures are in different stages of resolution; (5) the parents' or guardians' history is inadequate and incompatible with the demonstrable injuries; and (6) there is often a history of multiple admissions to hospital, and characteristically no new lesions appear during the child's stay in hospital (modified from Birrell and Birrell, 1968).

Leeds General Infirmary, Leeds LS1 3EX

BRIAN HARCOURT, F.R.C.S., D.o., Consultant Ophthalmic Surgeon DAVID HOPKINS, F.R.C.S., D.o., Senior Registrar in Ophthalmology
Despite detailed descriptions of external, visceral, skeletal, craniocerebral, and psychiatric findings in affected children (Caffey, 1946; Silverman, 1953; Kempe et al., 1962; Griffiths and Moynihan, 1963; McCort and Vaudagna, 1964; Cameron et al., 1966; Isaacs, 1968; Sussman, 1968) little attention has hitherto been directed to the ophthalmic manifestations. It is therefore our purpose to present the ocular findings in 11 young children who fulfil the diagnostic criteria of the syndrome so as to draw further attention to this important aspect of the disorder, demonstrating that in some cases severely defective vision may be a principal feature of a surviving child's permanent disability.

\section{Case Reports}

Tables have been used in order to present a summary of the principal general manifestations (Table I) and of the ophthalmic manifestations (Table II) in all the patients examined in this study. The ophthalmic examinations were carried out at intervals ranging from a few days to three years after the major episode of trauma, and the progress of most of the patients has

TABLE I-Case Histories: General Manifestations

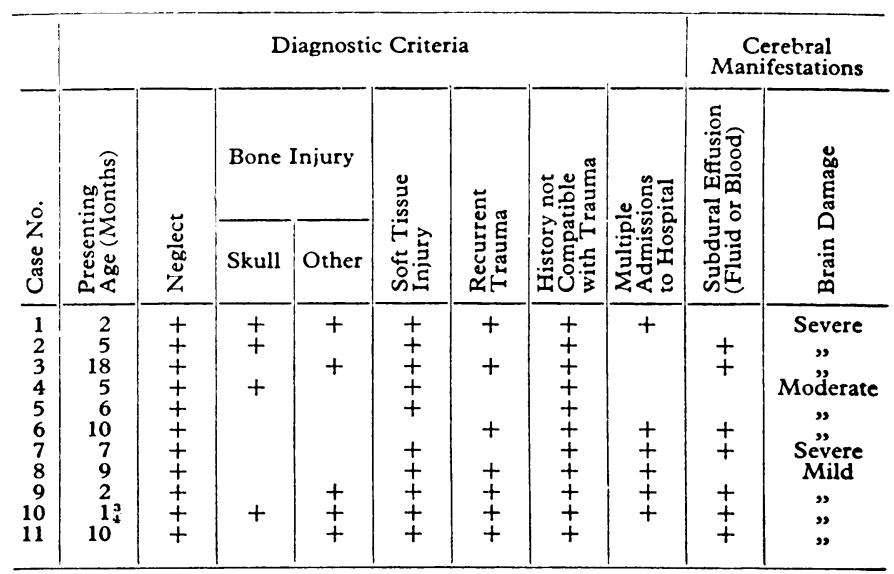

